\title{
Glomalin Production and Infectivity of Arbuscular-Mycorrhizal Fungi in Response to Grassland Plant Diversity
}

\section{R. L. Burrows}

Plant Science Department, South Dakota State University, Rapid City, USA.

Email: Rhoda.Burrows@sdstate.edu

Received September $14^{\text {th }}, 2013$; revised December $4^{\text {th }}, 2013$; accepted December $27^{\text {th }}, 2013$

Copyright (C) 2014 R. L. Burrows. This is an open access article distributed under the Creative Commons Attribution License, which permits unrestricted use, distribution, and reproduction in any medium, provided the original work is properly cited. In accordance of the Creative Commons Attribution License all Copyrights (C) 2014 are reserved for SCIRP and the owner of the intellectual property R. L. Burrows. All Copyright (C) 2014 are guarded by law and by SCIRP as a guardian.

\begin{abstract}
Arbuscular-mycorrhizal fungi (AMF) are integral components of most terrestrial ecosystems, with complex interactions between plants and AMF. Our study assessed the impact of plant diversity of native grassland species on AMF infectivity and production of glomalin, an AMF hyphal glycoprotein that may play an important role in soil aggregation. The study was conducted over a 3-year period in field plots planted with 1, 2, 8, or 16 plant species. The mycorrhizal infection potential (MIP) of the plots was assayed in the greenhouse. Glomalin production and MIP were lowest in monocultures and were more closely correlated with plant diversity than with plant cover. Spore density was also greater in higher diversity plots. Lower AMF activity in monoculture plots may contribute to lower productivity and soil quality in plant monocultures. Immunoreactive glomalin levels varied seasonally, with higher levels in late summer than in late spring. Positive correlations were found between glomalin levels and spore density, and between MIP and spore density, but not between MIP and glomalin.
\end{abstract}

\section{KEYWORDS}

Arbuscular Mycorrhizae; Glomalin; Diversity; Extraradical Hyphae; Soil Aggregation

\section{Introduction}

Arbuscular-mycorrhizal fungi (AMF) form symbiotic relationships with plant roots and are integral components of the majority of terrestrial ecosystems, functioning in nutrient uptake and cycling [1]. Evidence is accumulating for "selectivity", if not specificity, between AMF and their plant hosts [2-5]. The composition of the AMF community responds to changes in the plant community [6-10]. Greenhouse studies [9,11] have shown that spore production of specific AMF species can be differentially influenced by host species. In a field study, Johnson et al. [12] found that five closely related grass species caused divergence in AMF community composition of initially identical soils. Host species may also affect the amount of hyphal growth of individual AMF species [13] or may modify the species composition of the fungal community by "selecting" species which colonize roots and soil more or less aggressively [7, 9].

Plant species diversity can also impact hyphal growth and activity of the associated AMF, directly or indirectly [7]. Lower spore densities and AMF species richness were found in field plots with low plant species diversity compared to those with higher species diversity [14]. More diverse plant communities may contain a widened range of root growth phenologies or of peak periods of photosynthate production or transport to the roots (e.g., $\mathrm{C}_{3}$ vs. $\mathrm{C}_{4}$ plants), which could lead to hyphal growth over longer periods throughout the growing season $[15,16]$. Increased plant species richness has also been shown to lead to increases in plant biomass [17-19], with concurrent increases in both fixed carbon and root surface available to support AMF growth.

This influence of host species diversity on hyphal growth may have considerable impact on the soil environment, as AMF hyphae can play a substantial role in 
maintaining soil structure [20,21]. Not only do these hyphae provide a physical framework for soil aggregates [22], they contain a glycoprotein, glomalin, which may act as a water-stable cementing agent for soil particles [20, 23-27]. Glomalin-reactive soil protein (GRSP) has been correlated with the degree of soil aggregation in various soil types [28,29] and glomalin may have an even stronger effect on aggregation than the hyphal network [24]. Thus GRSP levels may serve as a useful indication of AMF effect on soil structure.

Our objective in this study was to evaluate root colonization, mycorrhizal infection potential (MIP), and glomalin production as indicators of AMF activity in plots of differing plant species richness. We hypothesized that increasing plant diversity would lead to increases in each of these indicators of AMF activity. We also tested whether changes in above-ground plant biomass, an observed effect of increased plant diversity, were correlated with changes in AMF activity. Finally, we evaluated the relationships among root colonization, MIP, and glomalin production in plots varying in plant species richness.

\section{Materials and Methods}

\subsection{Experimental Design}

We tested our hypotheses at the Cedar Creek LTER in East Bethel MN, USA (latitude $45^{\circ} 35^{\prime \prime} \mathrm{N}$, longitude $93^{\circ} 10^{\prime \prime} \mathrm{W}$ ) in field plots in which the number of plant species was experimentally controlled. These plots were established in 1994 to test effects of increasing plant biodiversity on ecosystem functioning [17;

http://www.lter.umn.edu/research/exper/e120/e120.html]. The $34211 \times 11 \mathrm{~m}$ plots were established on a former bromegrass pasture with soil type Nymore series sand, pH 5.9 - 6.5. The surface $50-100 \mathrm{~mm}$ of soil was removed to decrease the existing seedbank, and the remaining soil disked and seeded with native tallgrass prairie species. The particular plant species assigned to each of these plots was determined by independent random draw of the appropriate number of species $(1,2,4$, 8, or 16) from a common pool of 19 species (Table 1). This assignment of species by random draw minimizes the confounding effects of individual plant species. The plots were irrigated in 1995 and 1996 to help insure seedling establishment and were weeded throughout the experiment to exclude invading plant species.

In order to characterize AMF activity associated with various plant diversity levels in this experiment, in 1997 we randomly selected a subset of twenty-four plots from each of four (1, 2, 8, and 16-species) plant diversity levels. A $2.0 \times 0.5 \mathrm{~m}$ subplot was established within each selected plot for sampling over a three-year period. Plant biomass was estimated by visual assessment of percent
Table 1. Plant species in the Cedar Creek LTER biodiversity plots.

\begin{tabular}{cc}
\hline Plant Species & Type \\
\hline Agropyron smithii Rybd. & $\mathrm{C}_{3}$ \\
Bouteloua gracilis (HBK.) Lagasca & $\mathrm{C}_{3}$ \\
Elymus canadensis L. & $\mathrm{C}_{3}$ \\
Koeleria cristata (Lam.) P. Beauv. & $\mathrm{C}_{3}$ \\
Poa pratensis L. & $\mathrm{C}_{3}$ \\
Andropogon gerardii Vit. & $\mathrm{C}_{4}$ \\
Panicum virgatum L. & $\mathrm{C}_{4}$ \\
Schizachyrium scoparium & $\mathrm{C}_{4}$ \\
Sorghastrum nutans [L.] Nash & $\mathrm{C}_{4}$ \\
Achillea millefolium L. & Forb \\
Asclepias tuberosa L. & Forb \\
Liatris aspera Michx. & Forb \\
Monarda fistulosa L. & Forb \\
Solidago nemoralis Aiton. Gray. & Forb \\
Amorpha canescens Pursh. & Legume \\
Lespedeza capitata Michx. & Legume \\
Lupinus perennis L. & Legume \\
Dalea candida Michx. & Legume \\
Dalea purpurea Vent. & Legume \\
\hline
\end{tabular}

cover of individual plant species in each subplot in mid-summer of each year, a time selected because both early-season and late-season plant species were present. A $0.5 \times 0.4 \mathrm{~m}$ grid was placed over each $1 / 5$ th section of each subplot, and the percent of ground covered by each plant species in each grid was recorded separately, then averaged to obtain both total plant cover and cover by species. This process also provided a record of the actual number of plant species present in each subplot, which was often less than the treatment diversity level of the main plot.

\subsection{Soil Sampling}

Soil samples were taken coincident with vigorous growth of $\mathrm{C}_{3}$ grasses (mid-June of the first year [Y1], and midMay of the second year [Y2]); and again when $\mathrm{C}_{4}$ grasses were mature, (late-August Y1 and Y2, and early Sept. the third year [Y3]). At each sampling time, six $12.5 \times 150$ $\mathrm{mm}$ soil cores were taken from random locations within each subplot. The exact sampling locations in each subplot were randomly determined for each sample, and were adjusted as necessary to avoid previously sampled sites. The cores from each plot were thoroughly mixed and stored in plastic bags at $5^{\circ} \mathrm{C}$ until assessments of infection potential (within ten days), at which point the remaining soil was dried and stored at room temperature.

\subsection{Mycorrhizal Infection Potential}

Mycorrhizal infection potentials (MIPs) were assessed for all plots at each soil sampling date. Fifteen $\mathrm{ml}$ fresh inoculum (consisting of soil and roots) from each plot sample was mixed with $120 \mathrm{ml}$ steam-pasteurized Cedar Creek soil, and placed in a $40 \times 180 \mathrm{~mm}$ conetainer, then 
planted with a two-week-old seedling of Andropogon gerardii $L$. (germinated in vermiculite), a highly mycorrhizal $\mathrm{C}_{4}$ grass species. For all sampling times except for the first, this process was repeated with two additional 15 $\mathrm{ml}$ samples from each soil sample bag, so that there were a total of three conetainers for each soil sample. Because of low infection numbers in Y1, starting Aug. Y2, the inoculum level was increased to $30 \mathrm{ml}$. The plants were maintained in the greenhouse at approximately $25^{\circ} \mathrm{C}$ with $14 \mathrm{hr}$ of daylight under high intensity discharge lamps. After 35 - 40 days, the plants were harvested for evaluation of root colonization. Roots from each conetainer were washed separately, cleared in $10 \% \mathrm{KOH}$ for one hour at room temperature, and stained with aniline blue (0.05\% in $70 \%$ acidified glycerol [30]. Fourteen $12-\mathrm{mm}$ root sections were selected randomly from each plant and mounted onto slides, and colonization was assessed by determining the percent of root containing vesicles, arbuscules, and/or AMF hyphae in a minimum of 140 fields of view per slide (100× magnification). The results of the three samples for each plot at each sampling were averaged prior to statistical analyses.

\subsection{Field Root Colonization}

Roots sieved from the soil cores from each dried field plot sample were processed and evaluated in the same manner as those from the infection potential assessments (see above), except that clearing was accomplished by autoclaving the roots in $10 \% \mathrm{KOH}$ for seven minutes. Because the fourteen root sections examined were randomly selected from each field plot sample, except for monoculture plot samples, they contained roots from a mixture of plant species.

\subsection{Spore Counts}

At each sampling, a $25 \mathrm{~g}$ dried soil subsample from each plot was wet-sieved and spores subsequently identified [14], counting those of each distinct species or morphotype.

\subsection{Glomalin Determination}

We assayed glomalin using two methods, the Bradford total protein, and an indirect enzyme-linked immunosorbent assay (ELISA). The Bradford-reactive soil protein assay measures the total GRSP present in a sample, and has the advantage of ease and rapidity. The ELISA method measures the portion of total GRSP that reacts with the monoclonal antibody developed specifically to detect glomalin on hyphae. Confidence that the GRSP are of AMF origin is considered highest for the immunoreactive GRSP [23], and this portion is also more closely related to soil aggregate stability than is the total GRSP $[23,28]$. However, results of the two methods have been found to be highly correlated.

To determine current-season deposition of GRSP, strips of horticultural landscape fabric were placed in the soil to adsorb the glycoprotein that was deposited as AMF hyphae grew across them [31]. These hyphal traps were put into place in conjunction with Y1 and Y2 field soil samplings, and separately in May of Y3. For each of the six soil core holes in each subplot, a $30 \times 140 \mathrm{~mm}$ (Y1) or $40 \times 150 \mathrm{~mm}(\mathrm{Y} 2$, Y3) strip of 20-mil-thick polyethylene landscape plastic (WeedBlock, Easy Gardner, P.O. Box 21025, Waco, TX, USA) was inserted vertically into the soil core hole, taking care to insure that $1 \mathrm{~cm}$ of each strip remained above ground level. The hole was then carefully filled with soil from an adjacent core. After two months, trap strips were gently removed and the top $1 \mathrm{~cm}$ trimmed off. The strips from each plot were then rinsed, sonicated to remove adhering soil, and placed together into a large centrifuge tube containing 10 $\mathrm{ml} 20 \mathrm{mM}$ citrate at $\mathrm{pH} 7.0$. The tubes were then autoclaved $1 \mathrm{~h}$ at $121^{\circ} \mathrm{C}$ to extract the GSRP from the strips [31]. The citrate extractant containing solubilized GRSP was poured off and stored at $5^{\circ} \mathrm{C}$ until determination of glomalin content. Prior to determinations of total or immunoreactive protein, the citrate extracts were centrifuged at 10,000 g for $5 \mathrm{~min}$ to remove insoluble material, and were then diluted 1:10 in phosphate-buffered saline (PBS). In order to assess within plot variation of total glomalin production, in Y1 we separately tested six individual strips from each of sixteen randomly-chosen plots.

Bradford reactive soil protein: Total GRSP in years 1 and 2 was estimated by the Bradford protein assay using 96-well microtiter plates according to the method of Wright and Upadhyaya [26]. Four wells were filled with $50 \mu \mathrm{l}$ of diluted extract from each subplot sample, and four blanks were filled with $50 \mu \mathrm{l}$ of $20 \mathrm{mM}$ citrate to correct for citrate in test samples. Fifty $\mu$ l of Bio-Rad Bradford dye (BioRad, Mellville, NY) were then mixed into each well, and color production in each well was read at $590 \mathrm{~nm}$ after $5 \mathrm{~min}$ incubation. Protein content was determined by comparison with quantitative standards consisting of bovine serum albumin in PBS in a range of $1.25-5.0 \mu \mathrm{g} / \mathrm{well}$. The means of the four wells for each extract sample are reported as $\mu$ g glomalin $/ \mathrm{cm}^{2}$ strip.

Immunoreactive (IR) glomalin: The immunoreactive protein contents of all samplings after the first were also determined by the ELISA method of Wright and Upadhyaya [26]. Each of the previously diluted citrate extract samples was diluted further (1:1 to 1:10 in PBS, based on visual assessment of the color of the extract), then $50 \mu \mathrm{l}$ of the diluted extract sample was added to four wells of a 96-well polyvinyl chloride plate, which was then dried at $37^{\circ} \mathrm{C}$ overnight. Each plate also contained, as quantitative standards, wells filled with 0.005 - 0.04 glomalin extract 
from a soil which consistently gave the same ELISA value as $0.5 \mu \mathrm{g}$ glomalin extracted from fresh hyphae of various AM fungi (Wright, personal communication). After drying, the plates were blocked with $2 \%(\mathrm{w} / \mathrm{v})$ nonfat milk in PBS for $15 \mathrm{~min}$. Plates were then incubated 1 $\mathrm{h}$ with each of the following reagents in consecutive order: Monoclonal antibody (MAb) 32B11, specific for glomalin [26]; biotinylated antimouse IgM antibody with a long spacer arm (Jackson ImmunoResearch Inc., West Grove, Penn., USA), and streptavidin peroxidase. Plates were washed extensively with PBS + Tween 20 between reagents. Color development was with ABTS [2,2" azino-bis(3-ethylbenzthiazoline-6-sulfonic acid)], read by a microplate reader (BioRad Model 2550) at $405 \mathrm{~nm}$ after 15 min incubation. The means of the four wells for each extract sample are reported as $\mu$ g glomalin $/ \mathrm{cm}^{2}$ strip.

\subsection{Statistical Analysis}

Percent colonization of roots from field samples and from MIP assay plants were arcsine transformed to normalize data prior to analyses for diversity treatment effects. Analyses of variance were performed on total and immunoreactive glomalin after log transformation to equalize variances. Where variances could not be sufficiently equalized, ANOVA was performed on ranktransformed glomalin data. Spearman rank correlations were used to assess relationships among glomalin, MIP, and spore counts within plots. Multiple regressions were used to assess the relationship of percent plant cover and the number of plant species present in each sample plot with total and IR glomalin production.

\section{Results}

\subsection{Mycorrhizal Infection Potential}

In all samplings of Y2 and Y3, soil inoculum from monoculture subplots resulted in significantly lower colonization of A. gerardii seedlings than did inoculum from 16-spp. plots (Figure 1). No significant differences in percent colonization of MIP assay plants were found among plant species diversity treatments in Y1. The May Y2 sampling was the only case in which MIP positively correlated with plant cover, and that was with the previous year"s cover only (Table 2). Infection potentials correlated positively with spore totals $(\mathrm{r}=0.22$ to 0.46 ; $\mathrm{p}$ $<0.05$ ) in Y2. MIPs were not correlated with glomalin levels, nor with MIPs from previous samplings (data not shown). No seasonal patterns of MIP were apparent.

\subsection{Field Root Colonization}

Overall root colonization increased over the three year period, from a low of $16 \%$ in the first sampling to a high of $65 \%$ in the final assessment. No significant differences

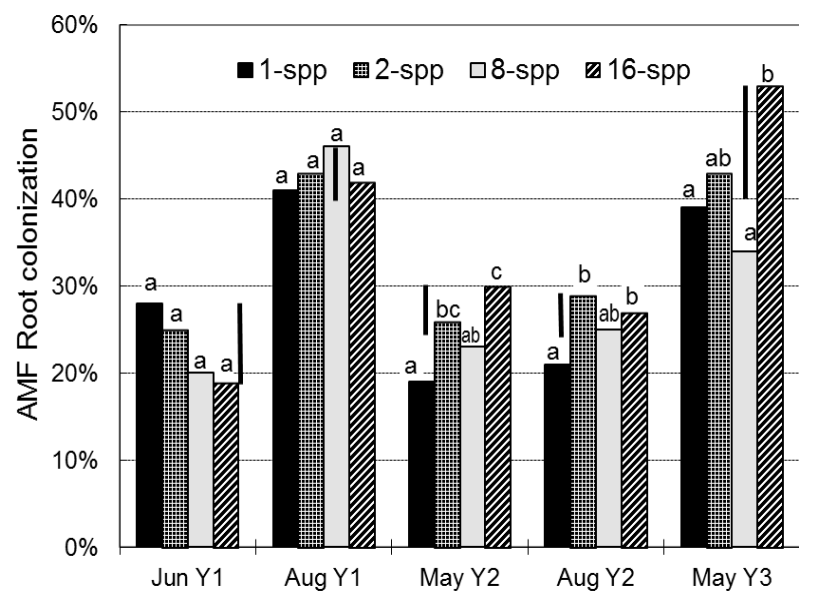

Figure 1. AMF colonization of Andropogon gerardii seedlings 35 - 40 days after inoculation with soil from Cedar Creek LTER, USA biodiversity plots planted with 1, 2, 8, or 16 plant species. Mean separations within each sampling time by Fisher's protected Least Significant Difference (LSD, $\mathrm{n}=24, \mathbf{p}=0.05$ ); bars indicate LSD.

were found at any sampling time in the percent colonization of field roots among diversity treatments (data not shown). Coefficients of variance from the ANOVAs were quite high ( $45 \%$ to $60 \%$ ), reflecting the wide diversity of plant hosts sampled. No significant correlations were found between root colonization in the field and any other parameter measured, including glomalin production, plant cover, MIP, or sporulation (data not shown).

\subsection{Spore Counts}

Spore density was significantly greater in higher diversity plots in the first three samplings; although the trends continued, the differences were not significant in the final two samplings (Figure 2).

\subsection{Glomalin}

Total (BRSP) and IR glomalin levels within each plot and sampling time were strongly positively correlated for all three sampling times in which both assays were used (Table 3). Strips from monoculture plots had less total and IR glomalin than those from plots with greater plant diversity (Figure 3). Total glomalin showed no seasonal trends, while IR glomalin levels were much higher in late-season samples than in early-season samples. The glomalin level of an individual plot tended to be positively correlated with the level found in the preceding sampling period, with the exception of a negative correlation between Aug Y2 and May Y3 (Table 3) The separate test of individual strips from the 16 plots indicated that glomalin was not equally distributed among strips: within-plot deviations of total glomalin ranged from 0.08 to 1.51 for plot means of 1.05 to 3.54 , respectively. 
Table 2. Spearman rank correlations among total (BRSP) and immunoreactive (IR) glomalin-related soil protein, mycorrhizal infection potentials (MIP), plant cover, number of plant species within each subplot, and AMF spore numbers. MIPs in Y1 and Y3 were not significantly correlated with any other variables.

\begin{tabular}{|c|c|c|c|c|c|c|c|c|c|c|}
\hline & \multirow{2}{*}{$\begin{array}{c}\text { Jun Y1 } \\
\text { BRSP }\end{array}$} & \multicolumn{2}{|c|}{ Aug Y1 } & \multicolumn{3}{|c|}{ May Y2 } & \multicolumn{3}{|c|}{ Aug Y2 } & \multirow{2}{*}{$\begin{array}{c}\text { May Y3 } \\
\text { IR }\end{array}$} \\
\hline & & BRSP & IR & MIP & BRSP & IR & MIP & BRSP & IR & \\
\hline \multicolumn{11}{|l|}{ Year 1: } \\
\hline Plant sp. \# & $0.30^{* * *}$ & $0.37^{* * *}$ & $0.43^{* * * *}$ & $0.28^{*}$ & $0.37^{* * *}$ & $0.44^{* * *}$ & & & & \\
\hline \% Cover & $0.38^{* * *}$ & $0.49^{* * *}$ & $0.53^{* * *}$ & $0.30^{* *}$ & $0.31^{* *}$ & $0.36^{* * * *}$ & & & & \\
\hline Spores-Jun & $0.33^{*}$ & $0.33^{* * * *}$ & $0.33^{* * *}$ & $0.22^{*}$ & n.s. & $0.30^{* *}$ & & & & \\
\hline Spores-Aug & $0.27^{*}$ & n.s. & n.s. & $0.23^{*}$ & $0.23^{*}$ & $0.34^{* *}$ & & & & \\
\hline \multicolumn{11}{|l|}{ Year 2: } \\
\hline Plant sp. \# & & & & & $0.35^{* *}$ & $0.32^{* *}$ & n.s. & n.s. & $0.23^{*}$ & n.s. \\
\hline \% Cover & & $0.33^{* *}$ & $0.35^{* * *}$ & & $0.24^{*}$ & $0.31^{* *}$ & n.s. & n.s. & n.s. & $0.23^{*}$ \\
\hline Spores-May & & n.s. & n.s. & $0.46^{* * *}$ & n.s. & n.s. & n.s. & n.s. & n.s. & $0.34^{* *}$ \\
\hline Spores-Aug & & & & $0.22^{*}$ & n.s. & n.s. & $0.26^{*}$ & n.s. & n.s. & n.s. \\
\hline \multicolumn{11}{|l|}{ Year 3: } \\
\hline Plant sp. \# & & & & & & & & & & $0.29^{* *}$ \\
\hline \% Cover & & & & & & & n.s. & $0.27^{*}$ & $0.33^{* *}$ & n.s. \\
\hline Spores-Sept & & & & & & & $0.32^{* *}$ & n.s. & n.s. & n.s. \\
\hline
\end{tabular}

n.s., ${ }^{*},{ }^{* *},{ }^{* * *}$, indicate correlations with $\mathrm{p}>0.05,<0.05,<0.01$, and $<0.001$, respectively.

Table 3. Spearman rank correlations between total (BRSP) and immunoreactive (IR) glomalin-related protein deposition onto landscape fabric traps placed in biodiversity plots.

\begin{tabular}{cccccc}
\hline & BRSP & IR & BRSP & IR & IR \\
\hline & Aug Y1 & Aug Y1 & May Y2 & May Y2 & Aug Y2 \\
BRSP & & & & & \\
June Y1 & $0.22^{*}$ & $0.25^{*}$ & n.s. & n.s. & \\
Aug Y1 & 1.00 & $0.94^{* * *}$ & $0.28^{*}$ & n.s. & \\
May Y2 & & & 1.00 & $0.55^{* * *}$ & n.s. \\
Aug Y2 & n.s. & & n.s. & $0.28^{*}$ & $0.87^{* * *}$ \\
IR & & & & & \\
Aug Y1 & & 1.00 & $0.32^{* *}$ & $0.25^{*}$ & n.s. \\
May Y2 & n.s. & & & 1.00 & $0.26^{*}$ \\
Aug Y2 & & & & & 1.00 \\
May Y3 & & & & n.s. & $-0.33^{* *}$ \\
\hline
\end{tabular}

n.s., ${ }^{*},{ }^{* *},{ }^{* * *}$, indicate correlations with $\mathrm{p}>0.05,<0.05,<0.01$, and $<0.001$, respectively.

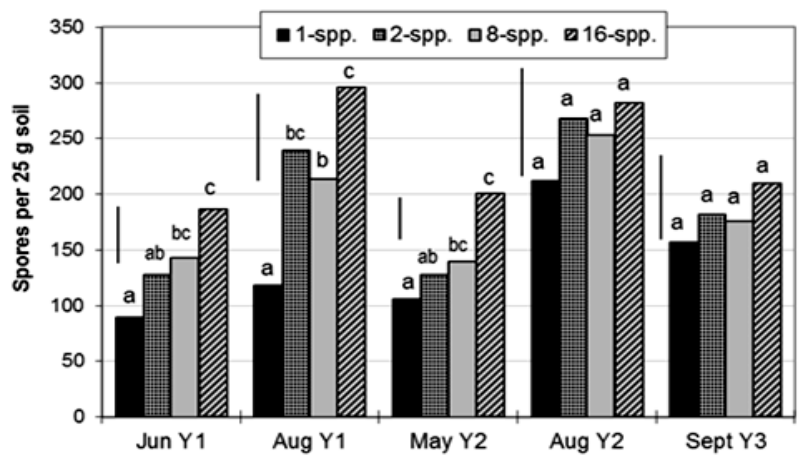

Figure 2. Plant diversity $(1,2,8$, or 16 species) effects on AMF spore density in Cedar Creek LTER, USA biodiversity plots. Mean separations within column groups (sampling times) by Fisher's protected Least Significant Difference (LSD, $n=24, p=0.05)$; bars indicate LSD.
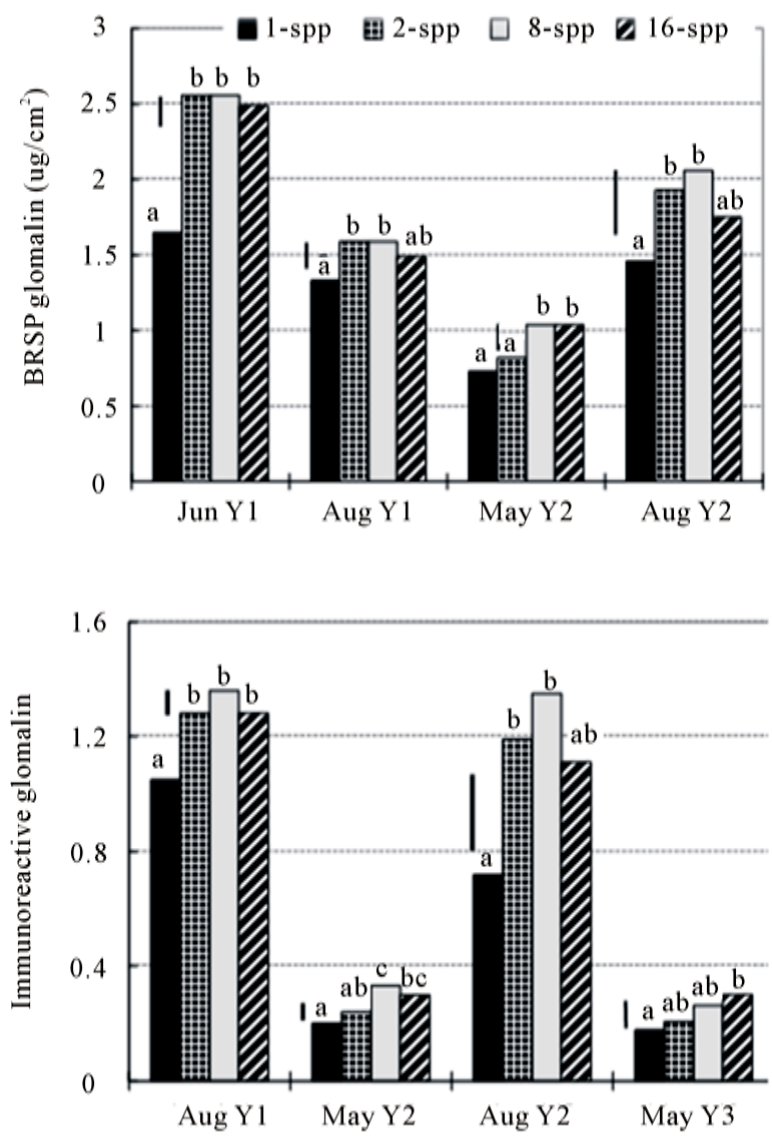

Figure 3. Plant diversity effects on total (BRSP) and immunoreactive (IR) glomalin deposition ( $\mathrm{ug} \mathrm{cm}^{-2}$ ) onto hyphal trap strips at the Cedar Creek LTER, USA. Mean separations within each sampling time by Fisher's protected Least Significant Difference (LSD, $n=24, p=0.05$ ); bars indicate LSD. 
Glomalin levels were positively correlated with plant cover of the same year, and that of the preceding or following years (Table 2). However, regression analyses that included both plant diversity and plant cover as independent variables showed that glomalin levels were significantly associated with percent cover in the first year only (Table 4). Plant diversity tended to have closer association with both IR and Bradford soil protein assessments of glomalin earlier in the growing season (Table 4).

Both total and IR glomalin levels were positively correlated with spore production (Table 2). In almost every case, however, glomalin values of each subplot were more closely correlated with spore counts of cores from the previous sampling than with spore counts of cores period. Glomalin levels were not predictive of future sporulation, as spore numbers were not significantly correlated with glomalin from previous sampling periods.

\section{Discussion}

Monocultures in this experiment had lower levels of glomalin production, spore production, and infectivity (MIP), compared to higher diversity plots. The lower glomalin production might be partially explained by the tendency of monocultures to have less plant cover and therefore less photosynthetic capacity and/or root tissue to support AMF hyphal growth. However, although glomalin was significantly correlated with plant cover in four out of five samples, regression analyses (Table 4) indicated that even when plant cover effects are accounted for, differences in glomalin levels can remain among plant diversity treatments.

There are several ways in which plant diversity might directly impact glomalin production. Previously, we found that plots with higher levels of plant diversity support a greater variety of AMF species [14]. Van der Heijden et al. [3] found that microcosms that contained the greatest numbers of AMF species also had the highest hyphal densities. They attributed this effect to increased possibility for positive feedbacks, given the greater array of specific plant-fungal combinations. An increase in the number of AMF species may also lead to a more completely filled array of temporally or spatially different ecological niches. Functional complementarity may be common within mycorrhizal communities [32]. Smith et al. [33], for example, report that Scutellospora calospora hyphae infecting Medicago truncatula absorbed P primarily from soil close to the roots, whereas those of Glomus caledonium (syn. Funneliformis caledonius) explored more distant areas.

A second means by which plant diversity might impact glomalin production is through the resulting greater time length of plant activity within more diverse plots. In our plots, individual host species within a diverse plot may have been active at slightly or widely different times during the season, for example, cool-season $\mathrm{C}_{3}$ vs. warmseason $\mathrm{C}_{4}$ grasses. This broader period of plant activity could lead to a more extended period of active hyphal growth and, consequently, increased glomalin production within a species-rich plot.

Glomalin from fresh hyphae and spores is generally $100 \%$ immunoreactive [26], so IR values may indicate more recent hyphal deposition. Our finding that the IR glomalin-related soil protein values were consistently lower than total (Bradford-reactive) values on these strips is consistent with this concept. Wright and Upadhyaya [31] found similar differences in the ratios of total protein to IR protein assays of glomalin on strips from an experiment in which Sorghum sudanese was inoculated with Gigaspora rosea, Glomus intraradices (syn. Rhizophagus intraradices), or Gl. caledonium. They suggested that differences in cultural conditions or in fungal isolates could cause variation in the proportion of the total glomalin deposition that is immunoreactive.

We found that IR glomalin quantities were lower in the early portion of the growing season. Seasonal variation in hyphal growth is likely, as much of these perennial plants' resources may be directed towards shoot growth during the earlier part of the season and be unavailable to the AMF in the roots, whereas late-season carbon acquisition is directed towards root tissues. Lutgen et al. [34] found similar seasonal fluctuations of both IR glomalin levels and external hyphal length in an intermountain grassland.

Despite the seasonal variation in IR but not total glomalin, the two were highly correlated in this experiment. Furthermore, IR as well as total glomalin levels of successive sampling dates were positively correlated. Consistency in relative protein values over time may indicate the relative stability of the mycorrhizal communities in each plot, at least in terms of hyphal growth.

Glomalin was unequally deposited across the subplot, as indicated by the high standard deviations of the strips we tested inidividually. Because locations of the hyphal traps differed each sample time, some variation between sample times may be due to this spatial variation across the plot, even with six replicates per subplot. However, glomalin deposition on trap strips was less highly correlated with spore counts from the exact location into which the traps were placed than with spore counts from the preceding sampling period. Since spore counts were more predictive of future glomalin deposition than they were of deposition in the eight weeks immediately following the sampling, there may be a lag period between spore production and subsequent hyphal growth, perhaps due to transitory spore dormancy.

Although glomalin levels are indicative of hyphal ac tivity, their failure to be predictive of future spore pro- 
Table 4. Regression coefficients for association between glomalin-related soil protein levels, subplot plant species number, and percent plant cover at the Cedar Creek LTER. All data was In-transformed prior to analyses to normalize variances.

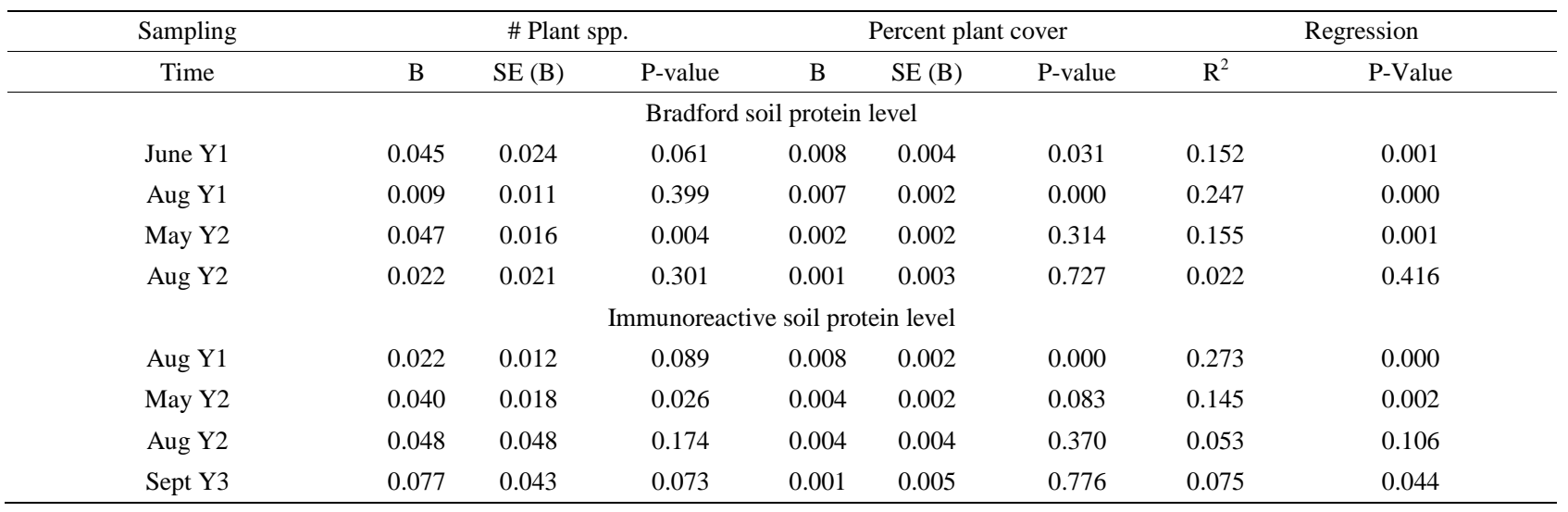

duction suggests a lack of close relationship between hyphal activity and subsequent sporulation. Alternatively, species that produce higher amounts of glomalin may not be prolific spore producers.

The lack of correlation between glomalin level and MIP may be due to the difference in infectivity of the relatively undisturbed hyphal networks surrounding the hyphal traps compared with that of soil cores that were disrupted during processing prior to MIP inoculation. This underscores the importance of using a variety of parameters to characterize AMF communities, as we have done here. The ability to assess production of glomalin adds one more tool for use in characterizing patterns and relationships of AMF hyphal activity in the field.

The lower hyphal activity and glomalin production of the monocultures in our study have implications for maintenance or restoration of soil tilth as well as soil carbon storage. Although a number of studies have compared various monoculture crop rotations, further research should compare glomalin-related soil protein levels and associated soil aggregation under monocultures with production under more diverse mixtures of crops. This may be particularly important for optimal restoration or preservation of soil health of highly-erodible soils. Because of its apparent recalcitrant nature, glomalin may sequester relatively large amounts of carbon in the soil [35]. Thus, studies of agricultural practices or other methods to increase soil carbon levels should include the effects on glomalin production.

In summary, we found that spore production, mycorrhizal infectivity and glomalin levels were lower in monocultures than in plots with higher plant diversity. Plant diversity had an effect on glomalin production independent of plant cover changes, and glomalin levels after the first year were more closely correlated with diversity than with plant cover. Thus, the number of plant species in an area has impacts on AMF activity that cannot be explained solely by associated changes in plant cover.

\section{Acknowledgements}

This research was funded in part by a University of Minnesota Graduate School Dissertation Fellowship to R. Burrows and by the Minnesota Agricultural Experiment Station. The Cedar Creek LTER biodiversity experiment is funded by the National Science Foundation.

\section{REFERENCES}

[1] M. F. Allen, “The Ecology of Mycorrhizae,” Cambridge University Press, Cambridge, 1991.

[2] M. G. A. Van der Heijden, T. Boller, A. Wiemken and I. R. Sanders, "Different Arbuscular Mycorrhizal Fungal Species are Potential Determinants of Plant Community Structure,” Ecology, Vol. 79, No. 6, 1998, pp. 2082-2091. http://dx.doi.org/10.1890/0012-9658(1998)079\%5B2082: DAMFSA\%5D2.0.CO;2

[3] M. G. A. Van der Heijden, J. N. Klironomos, M. Ursic, P. Moutoglis, R. Streitwolf-Engel, T. Boller, A. Wiemken and I. R. Sanders, "Mycorrhizal Fungal Diversity Determines Plant Biodiversity, Ecosystem Variability and Productivity," Nature, Vol. 396, 1998, pp. 69-72. http://dx.doi.org/10.1038/23932

[4] T. J. Danielle, A. Hodge, J. Peter, W. Young and A. Fitter, "How Many Fungi Does It Take to Change a Plant Community?” Trends in Plant Science, Vol. 4, No. 3, 1999, pp. 81-82. http://dx.doi.org/10.1016/S1360-1385(99)01380-1

[5] D. Johnson, P. J. Vandenkoornhuyse, J. R. Leake, L. Gilbert, R. E. Booth, J. P. Grime, J. P. W. Young and D. J. Read, "Plant Communities Affect Arbuscular Mycorrhizal Fungal Diversity and Community Composition in Grassland Microcosms,” New Phytologist, Vol. 161, No. 2, 2003, pp. 503-515. http://dx.doi.org/10.1046/j.1469-8137.2003.00938.x

[6] R. C. Anderson, A. E. Liberta and L. A. Dickman, "Interaction of Vascular Plants and Vesicular-Arbuscular Mycorrhizal Fungi across a Soil Moisture-Nutrient Gradient,” 
Oecologia, Vol. 64, No. 1, 1984, pp. 111-117. http://dx.doi.org/10.1007/BF00377552

[7] N. T. Hausmann and C. V. Hawkes, "Plant Neighborhood Control of Arbuscular Mycorrhizal Community Composition,” New Phytologist, Vol. 183, No. 4, 2009, pp. 11881200. http://dx.doi.org/10.1111/j.1469-8137.2009.02882.x

[8] N. C. Johnson, D. R. Zak, D. Tilman and F. L. Pfleger, "Dynamics of Vesicular-Arbuscular Mycorrhizae during Old Field Succession,” Oecologia, Vol. 86, No. 3, 1991, pp. 349-358. http://dx.doi.org/10.1007/BF00317600

[9] J. D. Bever, J. B. Morton, J. Antonovics and P. A. Schultz, "Host-Dependent Sporulation and Species Diversity of Arbuscular Mycorrhizal Fungi in a Mown Grassland," Journal of Ecology, Vol. 84, No. 1, 1996, pp. 71-82. http://dx.doi.org/10.2307/2261701

[10] A. H. Eom, D. C. Hartnett and G. W. T. Wilson, "Host Plant Effects on Arbuscular Mycorrhizal Fungal Communities in Tallgrass Prairie,” Oecologia, Vol. 122, No. 3, 2000, pp. 435-444. http://dx.doi.org/10.1007/s004420050050

[11] R. Sanders and A. H. Fitter, "Evidence for Differential Responses between Host-Fungus Combinations of Vesicular-Arbuscular Mycorrhizas from a Grassland,” Mycological Research, Vol. 96, No. 6, 1992. pp. 415-419. http://dx.doi.org/10.1016/S0953-7562(09)81084-8

[12] N. C. Johnson, D. Tilman and D. Wedin, "Plant and Soil Controls on Mycorrhizal Fungal Communities,” Ecology, Vol. 73, No. 6, 1992, pp. 2034-2042. http://dx.doi.org/10.2307/1941453

[13] R. M. Miller, "The Ecology and Vesicular-Arbuscular Mycorrhizae in Grass- and Shrublands,” In: G. R. Safir, Ed., Ecophysiology of VA Mycorrhizal Plants, CRC Press, Boca Raton, 1987, pp. 135-170.

[14] R. L. Burrows and F. L. Pfleger, "Arbuscular Mycorrhizal Fungi Respond to Increasing Plant Diversity,” Canadian Journal of Botany, Vol. 80, No. 2, 2002, pp. 120-130. http://dx.doi.org/10.1139/b01-138

[15] M. F. Allen, E. B. Allen and P. Stahl, "Differential Niche Response of Bouteloua gracilis and Pascopyrum smithii to VA Mycorrhizae," Bulletin of the Torrey Botanical Club, Vol. 111, No. 3, 1984, pp. 361-365. http://dx.doi.org/10.2307/2995917

[16] Z. Kabir and R. T. Koide, "Effect of Autumn and Winter Mycorrhizal Cover Crops on Soil Properties, Nutrient Uptake and Yield of Sweet Corn in Pennsylvania, USA,” Plant and Soil, Vol. 238, No. 2, 2002, pp. 205-215. http://dx.doi.org/10.1023/A:1014408723664

[17] D. Tilman, J. Knops, D. Wedin, P. Reich, M. Ritchie and E. Siemann, "The Influence of Functional Diversity and Composition on Ecosystem Processes,” Science, Vol. 277, No. 5330, 1997, pp. 1300-1302. http://dx.doi.org/10.1126/science.277.5330.1300

[18] D. Tilman, D. Wedin and J. Knopps, "Productivity and Sustainability Influenced by Biodiversity in Grassland Ecosystems,” Nature, Vol. 379, 1996, pp. 718-720. http://dx.doi.org/10.1038/379718a0

[19] A. B. Hector, B. Schmid, C. Beierkehnlein, M. C. Caldeira, M. Diemer, P. G. Dimitrakopoulos, et al., "Plant
Diversity and Productivity Experiments in European Grasslands," Science, Vol. 286, No. 5442, 1999, pp. 1123-1127. http://dx.doi.org/10.1126/science.286.5442.1123

[20] S. Bedini, E. Pellegrino, L. Avio, S. Pellegrini, P. Bazzoffi, E. Argese and M. Giovannetti, "Changes in Soil Aggregation and Glomalin-Related Soil Protein Content as Affected by the Arbuscular Mycorrhizal Fungal Species Glomus mosseae and Glomus intraradices," Soil Biology and Biochemistry, Vol. 41, No. 7, 2009, pp. 14911496. http://dx.doi.org/10.1016/j.soilbio.2009.04.005

[21] R. M. Miller and J. D. Jastrow, "Vesicular-Arbuscular Mycorrhizae and Biogeochemical Cycling," In: F. L. Pfleger and R. G. Linderman, Eds., Mycorrhizae and Plant Health, American Phytopathological Society, St. Paul, Minn., 1994, pp. 189-212.

[22] R. P. Schreiner and G. J. Bethlenfalvay, "Mycorrhizal Interactions in Sustainable Agriculture," Critical Reviews in Biotechnology, Vol. 15, No. 3-4, 1995, pp. 271-285. http://dx.doi.org/10.3109/07388559509147413

[23] C. M. Rillig, S. F. Wright and E. T. Eviner, "The Role of Arbuscular Mycorrhizal Fungi and Glomalin in Soil Aggregation: Comparing Effects of Five Plant Species," Plant and Soil, Vol. 238, No. 2, 2002, pp. 325-333. http://dx.doi.org/10.1023/A:1014483303813

[24] C. M. Rillig, "Arbuscular Mycorrhizae, Glomalin, and Soil Aggregation,” Canadian Journal of Soil Science, Vol. 84, No. 4, 2004, pp. 355-363. http://dx.doi.org/10.4141/S04-003

[25] P. K. Singh, M. Singh and B. N. Tripathi, "Glomalin: An Arbuscular Mycorrhizal Fungal Soil Protein,” Protoplasma, Vol. 250, No. 3, 2013, pp. 663-669. http://dx.doi.org/10.1007/s00709-012-0453-z

[26] S. F. Wright and A. Upadhyaya, "Extraction of an Abundant and Unusual Protein from Soil and Comparison with Hyphal Protein of Arbuscular Mycorrhizal Fungi," Soil Science, Vol. 161, No. 9, 1996, pp. 575-586. http://dx.doi.org/10.1097/00010694-199609000-00003

[27] S. F. Wright, M. Franke-Snyder, J. B. Morton and A. Upadhyaya, "Time-Course Study and Partial Characterization of a Protein on Arbuscular Mycorrhizal Hyphae during Active Colonization of Roots," Plant and Soil, Vol. 181, No. 2, 1996, pp. 193-203. http://dx.doi.org/10.1007/BF00012053

[28] S. F. Wright and A. Upadhyaya, "A Survey of Soils for Aggregate Stability and Glomalin, a Glycoprotein Produced by Hyphae of Arbuscular Mycorrhizal Fungi," Plant and Soil, Vol. 198, No. 1, 1998, pp. 97-107. http://dx.doi.org/10.1023/A:1004347701584

[29] S. F. Wright and R. L. Anderson, “Aggregate Stability and Glomalin in Alternative Crop Rotations for the Central Great Plains,” Biology and Fertility of Soils, Vol. 31, No. 3-4, 2000, pp. 249-253.

http://dx.doi.org/10.1007/s003740050653

[30] C. Grace and D. Stribley, "A Safer Procedure for Routine Staining of Vesicular-Arbuscular Mycorrhizal Fungi," Mycological Research, Vol. 95, No. 10, 1991, pp. 11601162. http://dx.doi.org/10.1016/S0953-7562(09)80005-1

[31] S. F. Wright and A. Upadhyaya, "Quantification of Arbuscular Mycorrhizal Fungi activity by the Glomalin 
Concentration on Hyphal Traps,” Mycorrhiza, Vol. 8, No. 5, 1999, pp. 283-285.

http://dx.doi.org/10.1007/s005720050247

[32] R. Koide, "Functional Complementarity in the Arbuscular Mycorrhizal Symbiosis [Commentary],” New Phytologist, Vol. 147, No. 2, 2000, pp. 233-235.

http://dx.doi.org/10.1046/j.1469-8137.2000.00710.x

[33] F. A. Smith, I. Jakobsen and S. E. Smith, "Spatial Differences in Acquisition of Soil Phosphate between Two Arbuscular Mycorrhizal Fungi in Symbiosis with Medicago truncatula," New Phytologist, Vol. 147, No. 2, 2000, pp. 357-366. http://dx.doi.org/10.1046/j.1469-8137.2000.00695.x

[34] E. R. Lutgen, D. Muir-Clairmont, J. Graham and M. C. Rillig, "Seasonality of Arbuscular Mycorrhizal Hyphae and Glomalin in a Western Montana Grassland," Plant and Soil, Vol. 257, No. 1, 2003, pp. 71-83. http://dx.doi.org/10.1023/A:1026224209597

[35] K. K. Treseder and M. F. Allen, "Mycorrhizal Fungi Have a Potential Role in Soil Carbon Storage under Elevated $\mathrm{CO}_{2}$ and Nitrogen Deposition," New Phytologist, Vol. 147, No. 1, 2000, pp. 189-200.

http://dx.doi.org/10.1046/j.1469-8137.2000.00690.x. 